\title{
Common sense please
}

\author{
Charlotte Waite \\ Chair of the BDA England Community Dental Services Committee
}

The BDJ Upfront section includes editorials, letters, news, book reviews and interviews. Please direct your correspondence to the News Editor,

Kate Quinlan at BDJNews@nature.com. Press releases or articles may be edited, and should include a colour photograph if possible.

$\mathrm{N}$ HS dentists rely on the NHS Business Services Authority (NHSBSA) to process dental forms for payment. Both are operating at a time of unprecedented pressure on the NHS and in an increasingly challenging environment. It could be argued that dentists need the strength and collective voice of the BDA now more than ever.

The strategic aims of each organisation reveal their focus and purpose. The BDA's mission statement tells us that it will:

- Promote the interests of its members

- Advance the art, science and ethics of dentistry

- Improve the nation's oral health.

But it goes further, setting out its values, beliefs and actions, which directly relate to the mission, including the BDA's commitment to use our influence for the benefit of members, the dental profession and patients.

The NHSBSA's purpose is to 'Support a better NHS' with a vision 'to be the delivery partner of choice for the NHS. One of its ambitious goals is to identify and deliver $£ 1$ billion savings for the NHS, whilst maintaining or improving outcomes for patients (http://www.nhsbsa.nhs.uk/what-we-do).

So, the BDA will use its influence to benefit patients and the NHSBSA will maintain or improve patient outcomes. Perfect! Yet for some time the BDA has been extremely concerned about the exponential, year on year, increase in the number of Penalty Charge Notices the NHSBSA has issued to dental patients in England. This is a $£ 100$ fine which is issued if a patient makes an incorrect declaration regarding exemption from NHS dental charges. NHS funds must be protected and those who are required to pay dental charges must do so. However, patients who don't have capacity to make financial declarations, such as those with learning disabilities or dementia, often require support from a third party. Typically, patients will attend with someone who understands

their needs, the reasonable adjustments required for the provision of care and how best this can be delivered, yet before any treatment can take place, a conversation must ensue about eligibility for free treatment. A simple tick in a box and a few signatures are required, but in reality it is far more complex. The information needed to make an accurate declaration about receipt of benefits or exemption certificates is often lacking. Carers often do not know and may indeed not be allowed to know this information, resulting in inaccurate declarations and fines for vulnerable patients.

The current system is inadequate and is undoubtedly contributing to what the BDA views as unacceptable health inequalities. Our patients deserve a system which is accessible

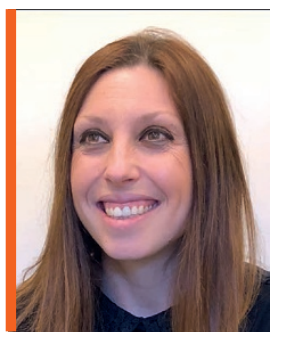

\section{'The current system is inadequate and is undoubtedly contributing to what the BDA views as unacceptable health inequalities...'}

to all and one that does not disadvantage those with protected characteristics. The reality is that even with information leaflets and explanations from dental staff, those making declarations on behalf of patients all too often don't possess the information and are therefore unable to make a declaration on behalf of the patient. The BDA's work on highlighting this issue was featured in a BBC report in October 2017. Two and a half million people read the story in the first 24 hours online. The overwhelming response led to the BBC publishing two follow-up stories.

The BDA has met with MPs who have raised concerns on behalf of their constituents and we will continue to work with them to lobby for change. A Welfare Rights Service brought to our attention its concerns regarding entitlement letters, which they felt were often of poor quality and misleading. An academic approached us to include this issue in her research project. A branch of Healthwatch brought us stories of patient concerns and suggested partnership working. Charities have offered support and will provide a patient voice.

The BDA met with representatives of the NHSBSA and NHS England at a Community Dental Service clinic, where they witnessed first-hand the problems patients and their carers had in making the declarations.

They were astonished at how much clinical time was taken up assisting patients with the paperwork. At the same time, the BDA presented its concerns, highlighted by a selection of individual cases gathered from colleagues across England.
Dialogue has continued with the NHSBSA and NHS England but as yet no suggestion of a workable solution has been forthcoming.

The development of an alternative declaration form was suggested by the BDA, using which an incorrect declaration would not generate a fine and would only request the payment of the patient charge, removing the stigmatisation of, and stress caused to, the patient. Is this really too much to ask?

The BDA will continue to press NHS England to join with all those who already recognise there is a problem and to provide a workable solution. In doing so we will continue to demonstrate our commitment to 'Use our influence for the benefit of members, the dental profession and patients.'

DOI: $10.1038 / s j . b d j .2018 .23$ 